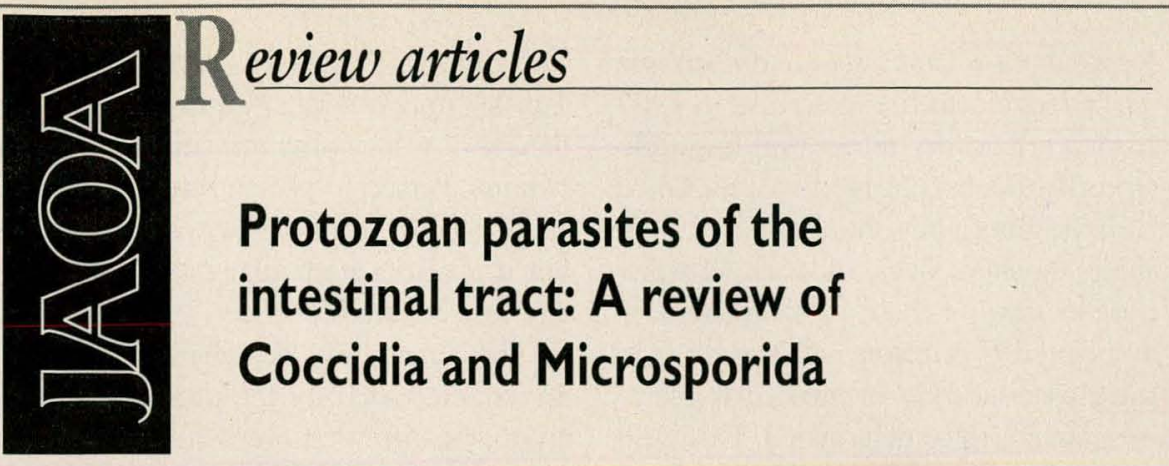

RICHARD COLLINS, PhD

Ubiquitous in nature, members of the Coccidia and Microsporida are being reported with increasing frequency in the immunocompromised as well as the immunocompetent population. These protozoans are primarily waterborne, but foodborne disease has also been reported. These organisms are responsible for acute, as well as protracted, cases of watery diarrhea with various other related sequelae. The Coccidia includes three genera-Cryptosporidium, Isospora, and Cyclospora. The latter two are of lesser importance in terms of morbidity and mortality. The Microsporida includes genera (Enterocytozoon, Encephalitozoon) only recently recognized as important agents of disease. Unlike the Coccidia, these organisms are more restricted to the immunocompromised population. Increased incidence and numbers of patients with prolonged diarrhea due to these forms indicate the need for increased clinical vigilance with regard to prevention, diagnosis, and treatment. (Keywords: Coccidia, Microsporida)

$T_{\mathrm{h}}^{\mathrm{h}}$ he description of "new" agents of human disease and nomenclature changes occur among all groups of pathogenic organisms. These changes are to be expected with advances in technology that enable more precise diagnosis of infectious diseases and greater knowledge of genetic relationships among the etiologic agents. In addition, the human immunodeficiency virus (HIV) pandemic and the related expansion of the immunocompromised population has contributed to an increase in the numbers of individuals infected with opportunistic pathogens. Increased travel opportunities and population migration due to natural and man-made calamities (for example, civil wars in Africa and elsewhere) have also served to expose more humans to these organisms. This is especially evident in gastrointestinal diseases,

At the time this article was written, Dr Collins was a professor of microbiology at the University of Ostoepathic Medicine and Health Sciences/College of Osteopathic Medicine and Surgery, Des Moines, lowa.

Correspondence to Richard F. Collins, PhD, Midwestern University, Division of Microbiology, $19555 \mathrm{~N}$ 59th Ave, Glendale, AZ 85308. with greater numbers of reported cases due to protozoans.

These emerging pathogens are members of two groups, the Coccidia and the Microsporida, commonly referred to as coccidians and microsporidians, respectively. The newly recognized importance of these organisms dictates that healthcare personnel develop a greater knowledge of them. This review presents essential information related to the natural history of these forms and the nature of the disease processes associated with them. In describing the disease presentations, an emphasis is placed on the immunocompetent patient, although the immunocompromised patient will also be included to a lesser extent. For readers with particular interest in disease manifestations in the immunocompromised host population, with an emphasis on the acquired immunodeficiency syndrome (AIDS), an extensive literature is available. ${ }^{1-10}$

\section{Etiologic agents}

The intestinal coccidians and microspo- ridians of humans are listed in Figure 1. Members of these groups are generally described as intracellular organisms that are common parasites of various vertebrates, including humans. The role of animals as reservoirs for human infections is not totally clear, but because related (possibly identical) organisms are commonly seen in livestock, feral animals, and pets, a strong possibility exists regarding their etiology for human disease. In addition, the taxonomic designations for the various organisms have been altered as new knowledge of relationships is reported; additional changes in nomenclature will probably occur.

The morphology of these forms is similar. Although the intracellular forms can be detected in biopsied specimens, the excreted stage can furnish the information required for specific diagnosis. The diagnostic forms (oocyts) of the coccidians can be distinguished by size differences and careful scrutiny of their structures using light microscopy.

The microsporidians produce a much smaller and therefore more difficult to detect, form (spore). Nonetheless, they can be detected by trained individuals conducting a vigilant search. The diagnostic forms are shown diagrammatically in Figure 2. The coccidian oocyst may not contain sporocysts (such as Cryptosporidium) but all species contain the sporozoite form. The "hatched" sporozoite develops into the ensuing life form. The microsporidian spore lacks these life-forms; instead, each spore injects its contents into the susceptible host cell to initiate the infection.

The strong presumption is that all of these organisms are transmitted primarily through the water supply. Essentially cosmopolitan, these organisms are more common in tropical and subtropical than in temperate climates and are more common in developing countries than in industrialized ones. The literature generally supports this perception. $11-13$ However, thorough population-based studies of prevalence or incidence are lacking.

\section{Cryptosporidium parvum}

The species designation usually accepted for the etiologic agent of human cryp- 


\section{Checklist}

Coccidia

Cryptosporidium parvum

Isospora belli

Cyclospora cayetanenis

\section{Microsporida}

$\square$ Encephalitozoon

(Septata) intestinalis

$\square$ Enterocytozoon

bieneusi

"Microsporidium" * spp

*Designation used for insufficiently characterized isolates.

Figure 1. Intestinal coccidia and microsporida of humans. tosporidiosis is Cryptosporidium parvum. The parasite was first described in 1907 from a laboratory mouse14; it has additionally been reported in chickens, turkeys, guinea pigs, horses, calves, pigs, sheep, monkeys, dogs, and cats. Whether the identities of these forms as humanassociated $C$ parvum will stand up to the closer scrutiny of molecular methods remains to be determined. This welltraveled organism can be described as a cause of zoonotic disease, based on various reports. ${ }^{15-18}$ However, it is probably more commonly transmitted person-toperson or by waterborne spread, although an outbreak associated with foodborne transmission has also been reported. ${ }^{19}$ Abundant literature on cryptosporidiosis has appeared during the past decade and some rather extensive reviews are available.4,20-23 Among the plethora of references are a number pertaining to the well-publicized outbreak that occurred in Milwaukee, Wis.24-26
This outbreak, as well as earlier ones in Texas 27 and Georgia,28 underscore the danger of waterborne transmission of $\mathrm{C}$ parrum. Person-to-person spread is especially noted within the gay community, but it is also a particular hazard in the day care setting. $29-34$

These organisms, like other coccidians, are characterized by the production of an oocyst form that eventually contains the infective sporozoites. When ingested, these forms can initiate an infection of the small intestine, the severity of which is pronounced in persons infected with the HIV.20 In a study of healthy volunteers, the infective dose was similar to that for Giardia (lamblia) intestinalis, a mean dose of 132 oocysts. 35 C parrum differs from its coccidian relatives in that its developmental stages occur in an intracellular, extracytoplasmic location, rather than deep within the host's cells. The reinfection of host cells by merozoites occurs, and in addition there are thin-

\begin{tabular}{|c|c|c|c|c|}
\hline Microsporidium & Cryptosporidium & Cyclospora & 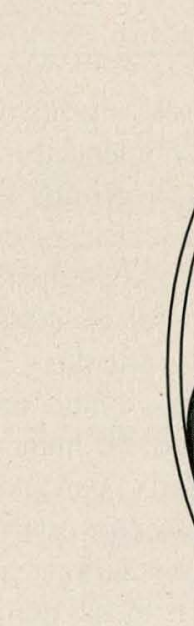 & Isospora \\
\hline Characteristics & Microsporidium & Cryptosporidium & Cyclospora & Isospora \\
\hline Oocyst size $(\mu \mathrm{m})$ & - & $4-6$ & $8-10$ & $20-30 \times 10-19$ \\
\hline No. of sporocysts & - & 0 & 2 & 2 \\
\hline No. of sporozoites/sporocyst & - & 4 (per oocyst) & 2 & 4 \\
\hline Spore size & $1-5$ & - & - & - \\
\hline
\end{tabular}

Figure 2. Comparative morphology of the diagnostic forms of microsporidian and coccidian agents of intestinal disease (Adapted from Gardiner CH, Fayer R, Dubey JP: An Atlas of Protozoan Parasites in Animal Tissues. Handbook No. 651, US Department of Agriculture, Washington DC, 1988; and Garcia LS, Bruckner DA: Diagnostic Medical Parasitology. Washington, DC, ASM Press, 1993.) 


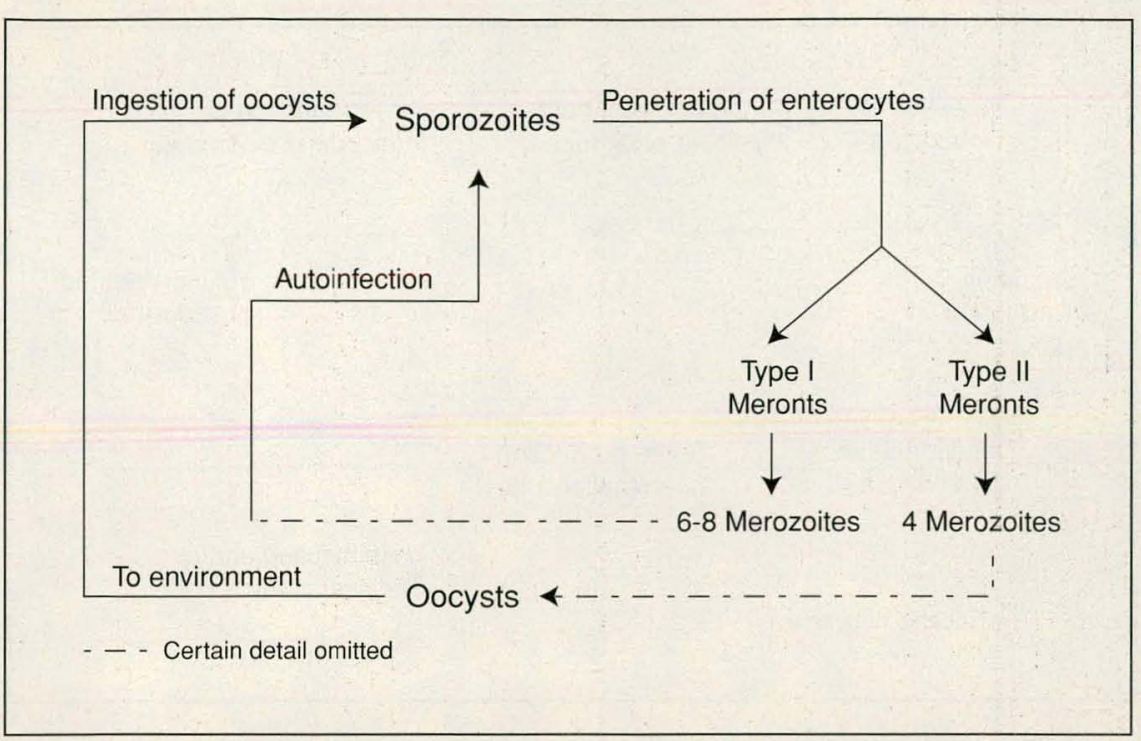

Figure 3. The life cycle of Cryptosporidium parvum in humans.

walled oocysts that can excyst within the patient's intestine, with the potential for overwhelming autoinfection (Figure 3).

The generally used permanent stains (trichrome, iron hematoxylin) for intestinal protozoan parasites do not adequately stain the cryptosporidia. The oocysts and their internal sporozoites are detectable in wet mounts, but this requires a skill level that may be lacking in laboratories unaccustomed to diagnosis of the cryptosporidia. The modified acid-fast stain is usually adequate for detecting the relatively small oocyst, but it will not reveal the internal morphology and is, therefore, a presumptive test. Definitive diagnosis is possible with various immunolabeling and fluorescent antibody methods that are commercially available. These techniques are highly specific, but sensitivity varies depending on the kit used. 36 In addition, the added expense may not be justified unless one is dealing with a population at higher risk for presence of the infection.

\section{Isospora belli}

Although universal agreement does not prevail regarding the number of species of Isospora that can cause human disease, most reports designate $I$ belli for the intestinal cases. A review of this genus has recently been published. ${ }^{37}$ Cosmopolitan in its geographic distribution, this microorganism is considered to be only a human parasite; no nonhuman reservoir hosts have been identified. This coccidian inhabits the epithelial cells of the small intestine and has a life cycle that is very similar to that of Cryptosporidium. However, unlike $C$ parvum, it exists within a parasitophorous vacuole in the infected cell. 38 the United States; for example, it has not been reported in Iowa since 1993.39 This absence may reflect a true lack of regular occurrence; its oocysts are relatively large $(20-30 \mu \mathrm{m} \times 10-19 \mu \mathrm{m})$ and are less likely to be overlooked in a properly conducted stool examination if fresh smears with high contrast or phase contrast microscopy are used. However, unless the laboratory technologist is forewarned, these microscopic techniques may not be used and thus the microorganism might be overlooked. As with Cryptosporidium, this organism will stain with the modified acidstains for intestinal protozoans.

\section{Cyclospora cayetanensis}

The most recent candidate for media coverage is Cyclospora cayetanensis. 40 This coccidian also affects the small intestine; it was first reported in 1979 in Papua, New Guinea. ${ }^{41}$ It has been reported with increasing frequency since
The organism is rarely reported in fast stain but not with the common

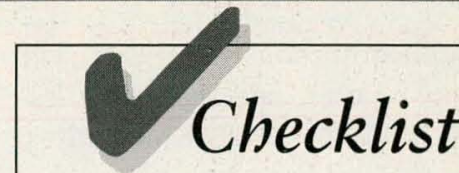

\section{$\square$ Encephalitozoon spp Intestine, cornea,kidney, nasal sinus, central nervous system; disseminated disease}

\section{$\square$ Enterocytozoon spp Intestine}

$\square$ Nosema spp
Cornea
$\square$ Pleistophora spp
Muscle
$\square$ "Microsporidium" *spp
Cornea

*Designation used for insufficiently characterized isolates.

Figure 4. Reported sites of human infection with microsporida.

then. Although it has been described in a variety of ways (coccidian-like bodies, cyanobacterium-like bodies, or bluegreen algae), it now has the more certain designation of $C$ cayetanensis. Although its life cycle has yet to be determined definitively, it is probably typical of that seen with other intestinal coccidians. Unlike the others, however, Cyclospora outbreaks have been associated with foodborne spread.42 Food items associated with clinical disease have included seasonal produce, particularly fresh fruits. $43-45$ However, waterborne spread of this organism is also likely.46-49 Personto-person spread is unlikely because of the time (days to weeks) required for oocyst maturation in the environment.

The modified acid-fast stain is not as effective for this species as for the other intestinal coccidians. This organism exhibits a highly variable staining reaction, and some oocysts will not be visualized.

\section{Microsporida}

Obligate intracellular parasites, the microsporidians occur predominantly 
in immunocompromised patients. The taxonomy of these species is even less settled than for their coccidian relatives. Their extensive host range means that species have been reported in every class of vertebrate as well as many invertebrates. 6 Before the AIDS pandemic, the microsporidians were generally unreported as causes of human disease. .50 In terms of gastrointestinal disease, the numbers of reported cases for immunocompromised hosts is more than 500 , compared with less than 20 for immunocompetent hosts. The numbers are likely higher for both groups, but currently available methods for diagnosis limit the ability to effectively screen for these organisms' presence. The diagnostic forms ("spores") are quite small (1 to $4 \mu \mathrm{m}$ ), but they are visible in histologic sections or stool specimens with the use of various stains and light microscopy. 51,52 Identification to the actual species level depends on electron microscopy, fluorescent antibody, or polymerase chain reaction (PCR) methods. $53-56$

Currently, four genera (Enterocytozoon, Encephalitozoon, Pleistophora, and Nosema) have documented associations with human disease; a fifth designation (Microsporidium) is not a valid genus, but it is used for those isolates with insufficient characteristics (Figure 4). A fifth genus, Septata, was recently described as a human pathogen. 57,58 However, the use of PCR and other techniques has demonstrated its identity with Encephalitozoon.59,60

The unique biology of the microsporidian features a highly resistant spore form, which when ingested or possibly inhaled, will evert a polar tubule. The extruded tubule, upon contact with the host cell membrane, permits the infectious form to enter the cell. Although the process is not necessarily a true injection of the parasite's protoplasm, it certainly serves that function. Replication and reinfection of other cells then occur with the eventual production of the spore form and its release to the environment. Some species are associated with disseminated disease and the mechanism(s) for this process is not fully understood. A typical life cycle is shown in Figure 5.

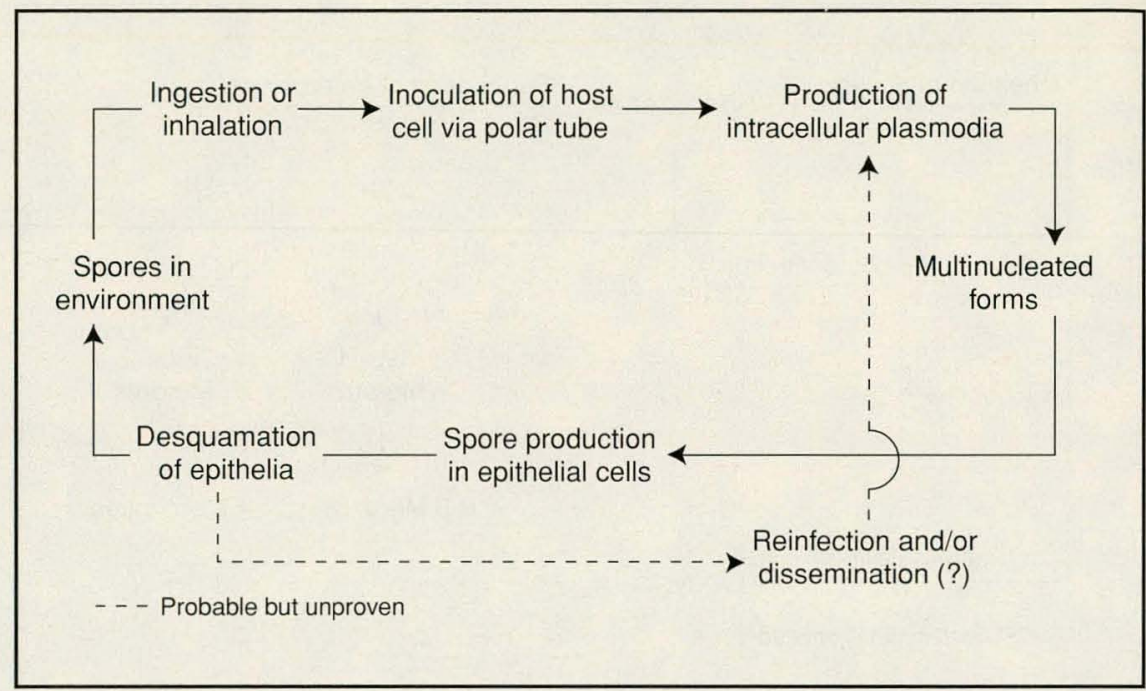

Figure 5. The life cycle of a "typical" microsporidian.

\section{Clinical considerations Coccidial infections}

The forms of intestinal coccidiosis are similar clinically, regardless of the etiologic agent. The difference in presentation generally relates to the patient's immune status. The infection is self-limited in the immunocompetent host, but it is protracted in the immunocompromised host, particularly when the individual is HIVpositive. $20,38,61$ The clinical manifestations of isosporiasis and cryptosporidiosis are indistinguishable. 38,62 The immunocompromised patient presents with chronic, profuse watery diarrhea; anorexia and weight loss commonly occur. Peripheral eosinophilia has been associated with isosporiasis but not with cryptosporidiosis. 38 This association is possibly spurious since concomitant helminthic infection may be present. Both infections will usually result in acute, self-limited intestinal diseases in immunocompetent hosts.4,63 However, more protracted forms of these diseases have been described in apparently immunocompetent patients.4,64 In eight outbreaks of cryptosporidiosis (consisting of a total of 221 patients), the duration of diarrhea ranged from 1 to 60 days with a median of 2 weeks. 4 Others have reported similar numbers, 65,66 but with possibly longer duration of symptoms in adults than in children. 66 In isosporiasis, duration of the infection is 6 weeks to 6 months. 12 In one exceptional case of isosporiasis, intermittent diarrhea of 20 years' duration and persistent eosinophilia were described. 67

Sudden onset, associated malaise, and infrequent fever are useful clues for cyclosporiasis. 68 In a series of $20 \mathrm{im}$ munocompetent patients with cyclosporiasis, the mean duration of illness was 35 days, with a range of 10 to 120 days 69 ; in two Peruvian patients, the self-limited diarrhea lasted 3 to 4 weeks. 70

\section{Microsporidial infections}

Unlike human intestinal coccidiosis, microsporidial infections of the gastrointestinal tract have been reported only in severely immunocompromised patients.71-81 Certain genera are limited to very few tissues, while others can infect multiple organs and are associated with disseminated disease (Table 2). It appears that these organisms are rarely capable of causing intestinal disease in immunocompetent hosts, but it is also too early in our accumulation of knowledge to determine whether this situation will remain unchanged. Only one documented case due to Enterocytozoon bieneusi in an immunocompetent patient has been reported. 82 In that patient, the diarrhea (4 to 5 soft stools per day) was self-limited, resolving after 2 weeks. Nevertheless, the concept of emerging diseases related to increased travel opportunities and an increasing immigrant population warrants the need for clinical 
awareness pertaining to both immunocompetent and immunodeficient hosts.

Documentation of risk groups is more clearly shown for cryptosporidiosis than for the other infections, with foreign travelers, animal handlers, children in day care centers, and immunocompromised patients (particularly AIDS patients) at greater risk. Based on our limited knowledge regarding the biology of the other related protozoans, it is reasonable to conclude that these same population groups are also at higher risk of infection with these other coccidian and microsporidian parasites. Certainly, the expanding list of etiologic agents for traveler's diarrhea must now include the agents described herein. The most reliable indicator for their omission from the differential diagnosis is absence of leukocytes or erythrocytes in the fecal specimen. Even though these protozoans are intracellular, they are not invasive in the immunocompetent host. The intracellular habitat does, however, stimulate a circulating antibody response, at least in the case of $C$ paruum infections.35,83-86 Although more sensitive procedures for diagnosis such as antibody detection and PCR are available, most laboratories will continue to rely on the classic light microscopic techniques for the forseeable future. Therefore, the clinician must be knowledgeable regarding these pathogens in order to alert the laboratory technologist to search for the possible presence of these microorganisms.

\section{References}

1. Robinson RD: Parasitic infections associated with HIV/AIDS in the Caribbean. Bull Pan Am Health Organ 1995;29:129-137.

2. Topasian M, Bia FJ: New parasites on the block emerging intestinal protozoa. Gastroenterologist $1994 ; 2: 147-159$

3. Gomes Morales MA, Atzori C, Ludovisi A, Rossi P et al: Opportunistic and non-opportunistic parasites in HIV-positive and negative patients with diarrhoea in Tanzania. Trop Med Parasitol 1995:46:109-114.

4. Crawford FG, Vermund SH: Human cryptosporid iosis. Crit Rev Microbiol 1988;16:113-159.

5. Whiteside ME, Barkin JS, May RG, Weiss SD, et al: Enteric coccidiosis among patients with the acquired immunodificiency syndrome. Am J Trop Med Hyg 1984;33:1065-1072

6. Weber R, Bryan RT, Schwartz DA, Owen RL: Human microsporidial infections. Clin Microbiol Rev 1994;7:426-461.
7. Gunnarsson G, Hurlbut D, DeGirolami PC, et al: Multiorgan microsporidiosis: Report of five cases and review. Clin Infect Dis 1995;21:37-44.

8. Weber R, Bryan RT: Microsporidial infections in immunodeficient and immunocompetent patients. Clin Infect Dis 1994;19:517-521.

9. Curry A, Canning EU: Human microsporidiosis. $J$ Infect 1993;27:229-236.

10. Goodgame RW: Understanding intestinal spore forming protozoa: Cryptosporidia, microsporidia, Isospora, and Cyclospora. Ann Intern Med 1996;124:429441.

1. Hoge CW, Shlim DR, Rajah R, et al: Epidemiology of diarrhoeal illness associated with coccidian-like organism among travelers and foreign residents in Nepal. Lancet 1993;341:1175-1179.

12. Restrepo C, Macher AM, and Radany EH: Dis seminated extraintestinal isosporiasis in a patient with acquired immune deficiency syndrome. Am J Clin Pathol 1987;87:537-542.

13. Henderson HE, Gillespie GW, Kaplan P: Isospora and traveler's diarrhea. Ann Intern Med 1987;106:908909.

14. Tyzzer EE: A sporozoan found in the peptic glands of the common mouse. Proc Soc Exp Biol Med 1907; 5:12-13.

15. Current WL, Reese NC, Ernst JV, et al: Human cryptosporidiosis in immunocompetent and immunod eficient persons. N Engl J Med 1983;308:1252-1257. 16. Anderson BC, Donnedelinger T, Wilkins RM, Smith $\mathrm{J}$ : Cryptosporidiosis in a veterinary student. J Am Vet Med Assoc 1982;30:408-409.

17. Reese NC, Current WL, Ernst JV, Bailey WS: Cryptosporidiosis of man and calf: A case report and results of experimental infections in mice and rats. Am J Trop Med Hyg 1982;31:226-229.

18. Shield J, Baumer JH, Dawson JA, Wilkinson PJ: Cryptosporidiosis-An educational experience. J Infect 1990;21:297-301

19. Millard PS, Gensheimer KF, Addiss DG, et al: An outbreak of cryptosporidiosis from fresh-pressed apple cider. JAMA 1994;272:1592-1596.

20. Navin TR, Juranek DD: Cryptosporidiosis: Clinical, epidemiologic, and parasitologic review. Rev Infect Dis 1984;6:313-327

21. Garcia LS, Current WL: Cryptosporidiosis: clinical features and diagnosis. Crit Rev Clin Lab Sci 1989; 27:439-460

22. Soave R, Armstrong D: Cryptosporidium and cryp tosporidiosis. Rev Infect Dis 1986;8:1012-1023.

23. Casemore DP: Epidemiological aspects of human cryptosporidiosis. Epidemiol Infect 1990;104:1-28.

24. Mac Kenzie WR, Schell WL, Blair KA, et al: Mas sive outbreak of waterborne Cryptosporidium infection in Milwaukee, Wisconsin: Recurrence of illness and risk of secondary transmission. Clin Infect Dis 1995 21:57-62.

25. Dreeszen PH: Milwaukee illness: A sick municipal water system's potential threat to lab animals. Lab Animal 1993;22(8):36-40

26. Gradus MS, Singh A, Sedmak GV: The Milwaukee Cryptosporidium outbreak: Its impact on drinking water standards, laboratory diagnosis, and public health surveillance. Clin Microbiol Newsl 1994;16:57-61.
27. D'Antonio RG, Winn RE, Taylor JP, et al: A waterborne outbreak of cryptosporidiosis in normal hosts. Ann Intern Med 1985;103:886-888.

28. Hayes EB, Matte TD, O'Brien TR, et al: Large community outbreak of cryptosporidiosis due to contamination of a filtered public water supply. $N$ Engl J Med 1989;320:1372-1376.

29. Tangermann $\mathrm{RH}$, Gordon $\mathrm{S}$, Wiesner $\mathrm{P}$, Kreckman $\mathrm{L}$ : An outbreak of cryptosporidiosis in a day-care center in Georgia. Am J Epidemiol 1991;133;471-476.

30. Taylor JP, Perdue JN, Dingley D, et al: Cryptosporidiosis outbreak in a day-care center. Am J Dis Child 1985; 139:1023-1025.

31. Combee CL, Collinge ML, Britt EM: Cryptosporidiosis in a hospital-associated day care center. Pediatr Infect Dis 1986; 5:528-532.

32. Heijbel H, Slaine K, Seigel B, et al: Outbreak of diarrhea in a day care center with spread to household members: The role of Cryptosporidium. Pediatr Infect Dis J 1987;6:532-535.

33. Stehr-Green J, McCaig L, Remsen HM, et al: Shedding of oocysts in immunocompetent individuals infected with Cryptosporidium. Am J Trop Med Hyg 1987;36:338-342.

34. Addiss DG, Steward JM, Finton RJ, et al: Giardia lamblia and Cryptosporidium infections in child day-care centers in Fulton County, Georgia. Pediatr Infect Dis J 1991;10:907-911.

35. DuPont HL, Chappell CL, Sterling CR, et al: The infectivity of Cryptosporidium parvum in healthy volunteers. N Engl J Med 1995:332;855-859.

36. Marshall M, Naumovitz D, Ortega, Y, Sterling C: Waterborne protozoan pathogens. Clin Micro Rev 1997;10(1): 67-85.

37. Lindsay DS, Dubey JP, Blagburn, BL: Biology of Isospora spp from humans, nonhuman primates, and domestic animals. Clin Micro Rev 1997; 10(1):19-34.

38. Marcial-Seoane MA, Serrano-Olmo J: Intestinal infection with Isospora belli. Puerto Rico Health Sci J 1995;14:137-140.

39. Organisms of interest. lowa Lab Hotline 1993; 32(4):9.

40. Dibbell J: Berry puzzling. This summer's stomach bug is still on the lam. Time 1996;148(2):59

41. Ashford RW: Occurrence of an undescribed coccidian in man in Papua New Guinea. Ann Trop Med Parasitol 1979;73:497-500.

42. Chambers J, Somerfeldt S, Mackey L, et al: Outbreaks of Cyclospora cayetanensis infection-United States, 1996. MMWR 1996;45(25):549-551.

43. Hofman J, Liu Z, Genese C,et al: Outbreaks of Cyclospora cayetanensis infection-United States, 1996. MMWR 1996;45(28):611-612.

44. Chew D, Caraballo R, Hofmann J, et al: Cyclospora cayetanensis infection associated with consumption of raspberries, New Jersey, 1996. Proc 36th ICAAC 1996;:LB25.

45. Fleming C, Caron D, Gunn JE, Barry MA: A foodborne outbreak of Cyclospora cayetanensis at a wedding. Proc 36th Interscience Conference on Antimicrobial Agents and Chemotherapy (ICAAC) 1996;LB24.

46. Ooi WW, Zimmerman SK, Needham CA: Cyclospora species as a gastrointestinal pathogen in 
immunocompetent hosts. J Clin Microbiol 1995;33: 1267-1269.

47. Long EG, Ebrahimzadeh A, White EH, et al: Alga associated with diarrhea in patients with acquired immunodeficiency syndrome and in travelers. J Clin Microbiol 1990;28:1101-1104.

48. Wurtz R: Cyclospora:A newly identified intestinal pathogen of humans. Clin Infect Dis 1994;18:620 623.

49. Carter R, Guido F, Jacquette G, Rapoport M: Outbreak of cyclosporiasis associated with drinking water. Proc 36th Interscience Conference on Antimicrobial Agents and Chemotherapy (ICAAC) 1996;K52.

50. Bryan RT: Microsporidiosis as an AIDS-related opportunistic infection. Clin Infect Dis 1995;21:S6265.

51. Garcia LS, Shimizu RY, Bruckner DA: Detection of microsporidial spores in fecal specimens from patients diagnosed with cryptosporidiosis. J Clin Microbio 1994;32:1739-1741.

52. DeGirolami PC, Ezratty CR, Desai G, et al: Diag nosis of intestinal microsporidiosis by examination of stool and duodenal aspirate with Weber's modified trichrome and uvitex 2B stains. J Clin Microbiol 1995;33:805-810

53. Fedorko DP, Nelson NA, Cartwright CP: Identification of microsporidia in stool specimens by using PCR and restriction endonucleases. J Clin Microbio 1995:33:1739-1741.

54. Aldras AM, Orenstein JM, Kotler DP, et al: Detection of microsposidia by indirect immunofluorescence antibody test using polyclonal and monoclonal antibodies. J Clin Microbiol 1994;32:608-612.

55. Visvesvara GS, DaSilva AJ, Croppo GP, et al: In vitro culture and serologic and molecular identification of Septata intestinalis isolated from urine of a patient with AIDS. J Clin Microbiol 1995;33:930-936.

56. DaSilva AJ, Schwartz DA, Visvesvara GS, et al: Sensitive PCR diagnosis of infections by Enterocyto zoon bieneusi (microsporidia) using primers based on the region coding for small-subunit rRNA. J Clin Microbiol 1996;34:986-987.

57. Cali A, Kotler DP, Orenstein JM: Septata intestinalis n.g., n.sp., an intestinal microsporidian associated with chronic diarrhea and dissemination in AIDS patients. J Euk Microbiol 1993,40:101-112.

58. Field AS, Hing MC, Milliken ST, Marriott DJ: Microsporidia in the small intestine of HIV-infected patients. A new diagnostic technique and a new species. Med J Aust 1993;158:390-394

59. Hartskeerl A, VanGool T, Schuitema ARJ, Didier ES, Terpstra WJ: Genetic and immunological characterization of the microsporidian Septata intestinalis Cali, Kotler and Grenstein, 1993: reclassification to Encephalitozoon intestinalis. Parasitol 1995;110:277. 285.

60. Baker MD, Vossbrinck CR, Didier ES, et al: Small subunit ribosomal DNA phylogeny of various microsporidia with emphasis on AIDS related forms. $J$ Euk Microbiol 1995;42:564-570.

61. Wurtz RM, Kocka FE, Peters CS, et al: Clinica characteristics of seven cases of diarrhea associated with a novel acid-fast organism in the stool. Clin Infect Dis 1993;16:136-138.

62. Pape JW, Johnson WD: Isospora belli infections. In Sun T (ed): Prog Clin Parasit 1991:2:119-127.
63. DeHovitz JA, Pape JW, Boncy M, Johnson WD: Clinical manifestations and therapy of Isospora belli infection in patients with the acquired immunodefi ciency syndrome. N Engl J Med 1988;315:87-90.

64. Faust EC, Giralbo LE, Caicedo G, Bonfante R: Human isosporosis in the Western hemisphere. Am Trop Med Hyg 1961;10:343-349.

65. Jokipii L, Pohjola S, Jokipii AMM: Cryptosporidium A frequent finding in patients with gastrointestinal symptoms. Lancet 1983:358-361.

66. Hunt DA, Shannon R, Palmer SR, Jephcott AE: Cryptosporidiosis in an urban community. $\mathrm{Br} \mathrm{Med}$ 1984;289:814-816.

67. Trier JS, Moxey PC, Schimmel EM, Robles E Chronic intestinal coccidiosis in man: intestinal morphology and response to treatment. Gastroenterology 1974;66:923-935

68. Chiodini PL: A 'new' parasite: Human infection with Cyclospora cayetanensis. Trans $R$ Soc Trop Med Hyg 1994;88:369-371

69. Gascon J, Corachan M, Bombi JA, et al: Cyclospo ra in patients with traveller's diarrhea. Scand J Infect Dis 1995;27:511-514.

70. Zerpa R, Uchima N, Huicho L: Cyclospora cayetanensis associated with watery diarrhoea in Peruvian patients. J Trop Med Hyg 1995;98:325-329.

71. Schwartz DA, Abou-Elella A, Wilcox CM, et al: The presence of Enterocytozoon bieneusispores in the lamina propria of small bowel biopsies with no evidence of disseminated microsporidiosis. Arch Pathol Lab Med 1995:119:424-428.

72. Joste NE, Rich JD, Busam KJ, Schwartz DA Autopsy verification of Encephalitozoon intestinalis (microsporidiosis) eradication following albendazole therapy. Arch Pathol Lab Med 1996;120:199-203.

73. Weber R, Sauer B, Lüthy R, Nadal D: Intestinal coinfection with Enterocytozoon bieneisi and cryptosporidium in a human immunodeficiency virus-infect ed child with chronic diarrhea. Clin Infect Dis 1993; $17: 480-483$

74. Cali A, Owen RL: Intracellular development of Enterocytozoon, a unique microsporidian found in the intestine of AIDS patients. J Protozool 1990; 37:145-155

75. Dore GJ, Marriott DJ, Hing MC, et al: Disseminated microsporidiosis due to Septata intestinalis in nine patients infected with the human immunodeficiency virus: response to therapy with albendazole. Clin Infect Dis 1995;21:70-76.

76. Sobottka I, Albrecht H, Schäfer H, Schottelius J, Visvesvara GS, et al: Disseminated Encephalitozoon (Septata) intestinalis infection in a patient with AIDS: Novel diagnostic approaches and autopsy-confirmed parasitological cure following treatment with albendazole. J Clin Microbiol 1995;33:2948-2952.

77. Schwartz DA, Bryan RT, Hewan-Lowe KO, et al Disseminated microsporidiosis (Encephalitozoon hellem) and acquired immunodeficiency syndrome. Arch Pathol Lab Med 1992;116:660-668.

78. Didier ES, Rogers LB, Brush AD, et al: Diagnosis of disseminated microsporidian Encephalitozoon hellem infection by PCR-southern analysis and successful treatment with albendazole and fumagillin. J Clin Micro biol 1996;34:947-952.

79. Orenstein JM: Microsporidiosis in the acquired immunodeficiency syndrome. J Parasitol 1991;77:843864.
80. Bryan RT: Microsporidiosis as an AIDS-related opportunistic infection. Clin Infect Dis 1995;21:S62 S65.

81. Shadduck JA, Orenstein JM: Comparative pathology of microsporidiosis. Arch Pathol Lab Med 1993; 117:1215-1219.

82. Sandfort J, Hannemann A, Gelderblom H, et al: Enterocytozoon bieneusi infection in an immunocompetent patient who had acute diarrhea and who was not infected with the human immunodeficiency virus. Clin Infect Dis 1994;19:514-516.

83. Campbell PN, Current WL: Demonstration of serum antibodies to Cryptosporidium sp. in normal and immunodeficient humans with confirmed infections. J Clin Microbiol 1983:18:165-169.

84. Soave R, Johnson WD: Cryptosporidium and Isospora belli infections. J Infect Dis 1988;157:225-229.

85. Ungar BLP, Gilman RH, Lanata CF, Perez-Schael I: Seroepidemiology of Cryptosporidium infection in two Latin American populations. J Infect Dis 1988 ; $157: 551-556$

86. Kuhls TL, Mosier DA, Crawford DL, Griffis J: Seroprevalence of cryptosporidial antibodies during infancy, childhood, and adolescence. Clin Infect Dis 1994; 18:731-735. 